\title{
A Comment on the Note: Dialectics and Infant Shaking
}

\author{
David L. Chadwick
}

Published online: 15 January 2014

(C) Springer Science+Business Media New York 2014

The author begins with an accurate observation that the discourse about "Abusive Head Trauma" (AHT) and "Shaken Baby Syndrome" (SBS) has become clouded by harsh rhetoric and that a dialectical approach to resolution is missing and necessary. The controversy has reached the Supreme Court in Cavazos v. Smith and confused some justices. The author also calls for "transdisciplinary" research about medical histories given to doctors in child injury cases and confessions of inflicted injuries with or without plea bargains given to law enforcement officers or prosecutors.

Unfortunately, there is no existing authority capable of imposing a rational dialectic process on the combatants in this conflict, and they themselves may see little value in attempts to engage the "other side" in a rational dialectical process. The "medical experts" who hold that the diagnoses are unscientific are not so much motivated by science as by economic considerations. Persons threatened with prolonged imprisonment for crimes are often willing and able to recruit large sums to compensate the expert witnesses who may assist them in securing better outcomes and the defense attorneys who organize the defenses welcome the "agnostic" stances the "experts" bring since they inject "reasonable doubt."

Medical Examiners who are public employees charged with determining causes of death in injury cases are often underpaid by myopic political entities, and a few have been lured to assist defendants in fatal child abuse cases. Once they "cross the line" to "the other side" they tend to stay connected to the defense. The prosecutors often cast them out.

The author correctly observes that the "agnostic position" is not widely supported. Narang (Narang 2011) notes that both individual medical doctors and medical societies heavily favor the view that both AHT and SBS are valid diagnostic constructs.

In a later article, Narang (awaiting publication) comments on the literature cited by the confused justices:

Setting aside the multiple concerns regarding the selection criteria for the articles, the irony in the citation of these articles is that the articles cited by the dissenting justices are actually so methodologically flawed, scientifically inaccurate, and the lowest level of evidencebased medical literature, that they would be reasonable examples of articles that are 'not even good enough to be wrong.'

The medical doctors who write and cite this literature are irresponsible (Chadwick and Krous 1997). They can and must be restrained by medical societies. A dialectic resolution is unlikely, and the best of research will not make irresponsible testimony unprofitable.

\section{References}

Chadwick, D. L., \& Krous, H. F. (1997). Irresponsible expert testimony by medical experts in cases involving the physical abuse and neglect of children. Child Maltreatment, 2, 313-321.

Narang, S. (2011). A Daubert Analysis of Abusive Head Trauma/ Shaken Baby Syndrome. Houston Journal of Health Law and Policy, 11(3), 505.
D. L. Chadwick $(\bowtie)$

San Diego State University, 4816 Rushville Lane,

La Mesa, CA 91941, USA

e-mail: dlchadwick@cox.net 